\title{
1987 E-MRS Meeting is Largest in History
}

\section{Senator Louis Jung, President of the European Parliament, Addresses Attendees}

The 1987 meeting of the European Materials Research Society was held June 2-5 at the Council of Europe building in Strasbourg, France. This was the largest meeting ever held by E-MRS, with more than 700 scientists in attendance. Included in the meeting program were three topical symposia and a one-day discussion session on high $T_{c}$ superconductors. In addition, short courses were introduced for the first time. Also held were meetings of various networks organized by E-MRS for the European Parliament, and the first meeting of the International Materials Research Committee. An added highlight was the address by the President of the European Parliament, Senator Louis Jung, during the conference banquet.

The Tuesday morning Plenary Session for all participants featured invited lectures by four distinguished scientists: "Structure of Fast Ion Conducting Glasses," by M. Balkanski (Laboratoire de Physique des Solides [associé au CNRS], Université Pierre et Marie Curie); "Fine Structure in Electron Energy Loss and Auger Spectra: New Approaches to the Local Geometry Determination at Surfaces and Interfaces of Solids," by J. Derrien (Laboratoire d'Etudes des Propriétés Electroniques des Solides-CNRS); "Electronic Structure of Semiconductors, Superlattices, and Heterostructures," by G. Landwher (Physikalisches Institut, Universität Würzburg); and "Acoustical Imaging: Past, Present and Future," by M.G. Somekh (University College London). (See the MRS BULLETIN, Vol. XII No. 3, March/May, 1987, p. 37 for summaries of these lectures.)

Unique to this year's meeting was a joint session held on Wednesday morning for all participants. The joint session comprised six talks of interest to all the participants:

"The Importance of Low Energy Ions in Controlling Film Properties," by J.M.E. Harper (IBM Research Laboratories, Yorktown Heights, New York);

"Metastable Materials for Films and Coatings," by Ch. Weissmantel (Technische Universität Karl-Marx-Stadt, Sektion Physik/EB, Karl-Marx-Stadt, GDR);

"Plasma Assisted CVD Diamond Films," by R. Meissier, A.R. Badzian, T. Badzian, K.E. Spaer, P. Bachmann, and R. Roy (Pennsylvania State University);

"Limited Reaction Processing: Growth of $\mathrm{Si} / \mathrm{SiGe}$ and Compound Semiconductor Heterostructure," by J.F. Gibbons (Stanford University, Stanford, California);
"Direct Formation of Thin Films and Epitaxial Overlayers at Low Temperatures Using a Low Energy (10-500 eV) Ion Beam Deposition System," by R.A. Zuhr, G.D. Alton, B.R. Appleton, N. Herbots, T.S. Noggle, and S.J. Pennycook (Oak Ridge National Laboratory, Oak Ridge, Tennessee); and

"Comparison of Amorphous Si Film Growth Mechanisms Using PlasmaAssisted and Hg-Photosensitized CVD," by J. Derrin (Equipe Synthèse de Couches Minces pour l'Energétique, Ecole Polytechnique, Palaiseau, France).

Attendance and response to the one-day discussion session on high temperature superconductivity was overwhelming. This session was organized very late in the planning for the meeting by K. Andres (Walter-Meissner-Institut für Tieftemperaturforschung) and B. Stritzker (KFA, Jülich). Interest in this topic is very intense in Europe (as it is in the rest of the world), and this was the first organized meeting to

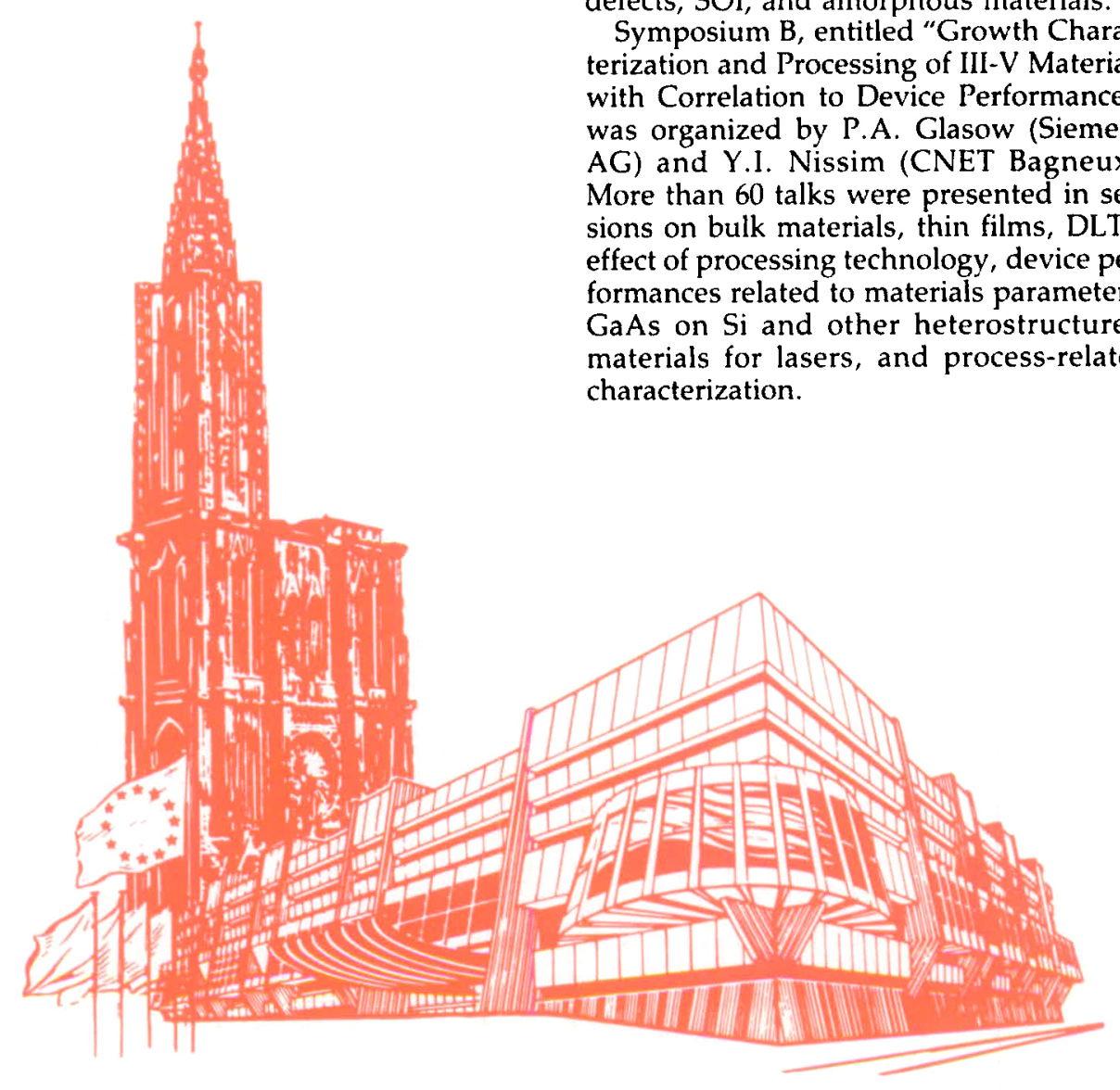

be held on this subject in Europe. More than 250 participants registered for this session alone, and the large conference room in the Council of Europe building was filled with approximately 500 participants throughout the day. Invited talks from international speakers were presented in the morning, followed by contributed talks in the afternoon. More than 35 presentations were given.

The three topical symposia focused on forefront topics in materials research. The topic for Symposium A, organized by V.T. Nguyen and A. Golanski (CNET Grenoble) and E.F. Krimmel (Siemens AG) was "Photon, Beam and Plasma Enhanced Processing." Over 100 abstracts were submitted, and parallel sessions were run on Wednesday afternoon, Thursday, and Friday, in addition to poster sessions. Included in Symposium A were sessions on fundamentals of beam-solid interactions; photon-induced processing; rapid thermal processing; electron, ion, and plasma processing; process-induced defects; SOI; and amorphous materials.

Symposium B, entitled "Growth Characterization and Processing of III-V Materials with Correlation to Device Performance," formances related to materials parameters, GaAs on $\mathrm{Si}$ and other heterostructures, materials for lasers, and process-related haracterization. 
Symposium C, "Amorphous Hydrogenated Carbon Films," was organized by P. Koidl (Fraunhofer-Institut für Angewandte Festkörperphysik) and P. Oelhafen (Institüt für Physik, Universität Basel). Sixty talks were organized into sessions on theoretical modeling, related materials, preparation, process characterization, film characterization, post deposition treatment, and hydrogenated amorphous carbon in fusion research.

Proceedings of the 1987 E-MRS Meeting in Strasbourg will be published by Les Editions de Physique, Avenue du Hoggar, B.P. 112, Zone Industrielle de Courtaboeuf, 91944 Les Ulis-Cedex, France; telephone 9073688 . In the United States, contact Materials Research Society, Publications Department, 9800 McKnight Road, Suite 327, Pittsburgh, PA 15237; telephone (412) 367-3012.

Short courses were offered for the first time at an E-MRS meeting. Inaugurating the program were two courses: Near Surface Characterization of Materials using $\mathrm{MeV}$ Ion Beam Techniques (organized by G. Amsel, Groupe de Physique des Solides, Paris, France) and Characterization of Semiconductors by Scanning Electron Microscopy (chaired by C. Donolato, CNR-Lamel, Bologna, Italy). More than 20 students participated in each course.

During the week, several European Network meetings were held. The European Community Commission has authorized the establishment of several European Networks in Materials Research. The purpose of the Networks is to focus on state-of-theart research in a particular field and to prepare a research proposal which would support a common effort by several European laboratories. E-MRS played an instrumental role in organizing the Networks in Materials Research for the European Community Commission (see the MRS BULLETIN, Vol. XII No. 3, 1987, p. 42).

The conference banquet for more than 250 participants was held in a pavilion associated with the Council of Europe. The highlight of the banquet was an address by the President of the European Parliament, Senator Louis Jung. Jung welcomed E-MRS to the Council of Europe and outlined his views on the need for cooperation in materials research. Materials and associated research contribute in a very direct way to the quality of life as we know it today, said Jung. Through cooperation, we can greatly increase our ability to improve the quality of life for people throughout the world, he continued.

Also held during the week was the inaugural meeting of the International Materials Research Committee. This Committee will be composed of representatives from each established MRS group and observers from developing MRS groups. The pur-

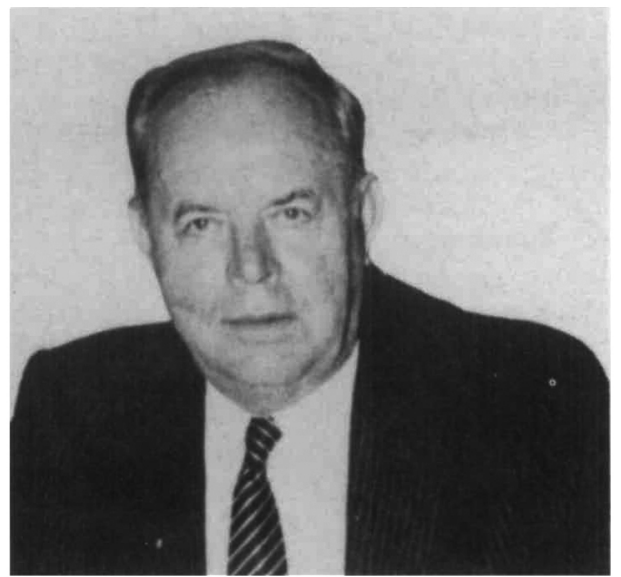

Senator Louis Jung, President of the European Parliament.

pose of the Committee is to strengthen international cooperation in materials research and to increase coordination and communication between the various MRS groups. Representatives from MRS and EMRS and an observer from the Chinese Joint Committee on Materials Research participated in the inaugural meeting. The Committee received a summary of MRS activities throughout the world and discussed ways to improve communication and coordination. The Committee also learned of plans by the Chinese to sponsor a Materials Research Meeting in 1990. The Chinese were invited to submit proposals for scientific cosponsorships for that meeting to the governing boards of MRS and E-MRS. Following the meeting, the General Secretary, G. Adinolfi, and the President of the Parliament, Senator Jung, hosted receptions for the International Committee participants. The next meeting of the International Committee will take place in Boston, Massachusetts, during the 1987 MRS Fall Meeting.

The week's activities in Strasbourg demonstrated the growing interest in Europe in MRS-style activities. The increase in activities by E-MRS is truly impressive, and attendance at the meeting demonstrated the response of the scientific community to the technical program. Plans are already under way for the next two EMRS meetings which will be held in Strasbourg in 1988 and 1989.

\section{High Temperature Superconductivity (International Discussion Meeting)}

Symposium Organizers: K. Andres (WalterMeissner-Institut für Tieftemperaturforschung, Garching, West Germany) and B. Stritzker (Institut für Festkörperforschung, KFA-Jülich, West Germany)

Because of the recent exciting developments in superconductors with high transi- tion temperatures, the E-MRS organizing committee decided in mid-April to host a one-day discussion meeting on "Superconducting Materials with High Transition Temperatures," primarily to bring together European researchers working on this topic. In spite of short notice, this symposium attracted almost 230 scientists from around the world. The morning session was devoted to five invited talks, three from the United States. Approximately 500 attendees filled the beautiful and impressive plenary room of the European Parliamentary Assembly in Strasbourg. Two parallel sessions in the afternoon, with 25 contributions each, were attended mainly by the 230 specialists.

The first invited speaker, J.G. Bednorz (IBM Research Laboratory, Zurich, Switzerland), outlined the history of the systematic search for superconductivity in conducting oxides containing Jahn-Teller ions. After an unsuccessful first try with nickel oxides, the search eventually led to the discovery of superconductivity in $\mathrm{La}_{1-x} \mathrm{Ba}_{\mathrm{x}} \mathrm{CuO}_{4-y}$. Bednorz also showed some data from a Yugoslavian group (Djurek et al.), who had seen the disappearance of electrical resistivity at $220 \mathrm{~K}$. B. Batlogg (AT\&T Bell Laboratories, Murray Hill, NJ) talked about the physical properties of both the $\mathrm{La}-\mathrm{Sr}-\mathrm{Cu}-\mathrm{O}$ and the Y-Ba-Cu-O superconductors. He stressed that both these superconducting materials are close to a structural instability, and that varying the oxygen stoichiometry affects the volume fraction of superconductivity more than it shifts the transition temperature, $T_{c}$. He detailed the recent and striking oxygenisotope shift measurements in the $\mathrm{YBa}_{2} \mathrm{Cu}_{3} \mathrm{O}_{7}$ superconductor which convincingly show the absence of such an isotope shift. This result does not support a conventional electron-phonon coupling mechanism in these superconductors.

J.D. Jorgenson (Argonne National Laboratory, USA) showed the results of extensive neutron-scattering structure work done by the Argonne group, pointing out the change in the structure of $\mathrm{YBa}_{2} \mathrm{Cu}_{3} \mathrm{O}_{7-\delta}$ as a function of temperature. On heating above $650^{\circ} \mathrm{C}$, the structure symmetry changes from orthorhombic to tetragonal and is accompanied by a loss of oxygen. L.E. Wenger (Wayne State University, Detroit, Michigan) reported on reverse Josephson effect experiments in $\mathrm{Y}-\mathrm{Ba}-\mathrm{Cu}$ O samples which showed small but clear traces of superconductivity at temperatures below about $240 \mathrm{~K}$. He pointed out, however, that these traces of superconductivity are not always reproducible and are also unstable. They are usually observed on fresh samples and disappear with time. The last talk in the morning session was given by M. Marezio (CNRS, Grenoble, France), who gave an account of the exten- 
sive $\mathrm{X}$-ray and neutron-diffraction structure work on $\mathrm{YBa}_{2} \mathrm{Cu}_{3} \mathrm{O}_{7 . \delta}$ done by the Grenoble group as a function of oxygen stoichiometry $\delta$. He pointed out that this structure can be viewed as an oxygen-deficient perovskite structure, with various degrees of order among the missing oxygen sites.

One afternoon session was devoted to preparation methods, structure, and electronic properties of the new materials; the other one to theory, magnetic properties, and applications.

Twelve groups presented results on differently prepared samples with high transition temperatures during one of the afternoon sessions. In particular, detailed structure determinations were presented which had been performed by x-ray diffraction, neutron scattering, and transmission electron microscopy. These methods were used for the characterization of the different phases and the detailed determination of the positions of the oxygen atoms depending on the preparation conditions and temperature. B. Raveau (Laboratoire CRISMAT, Caen, France) underlined the importance of a detailed characterization of both structure and chemistry of these ceramic materials as the only way to achieve reliable correlations to the superconducting properties of these samples. During the session it became apparent that none of the groups had produced real single-crystal material due to the microtwinning at the phase transition at $650^{\circ} \mathrm{C}$.

During the session on electronic properties, the results obtained by different experimental methods were presented, including electronic, optical and tunneling spectroscopy, specific heat, thermopower, pressure effect, and critical field. It was shown that replacement of $Y$ by rare earth elements did not significantly influence $T_{c}$. Contradicting conclusions were drawn concerning the validity of the BCS theory, i.e., the importance of the electron-phonon interaction in these materials. Measurements of the anisotropy of the critical field are difficult to interpret because of the broadening of the superconducting transition in a magnetic field. Also, the lack of good single-crystal material became obvious.

The second parallel session, on theory, began with an invited contribution from J. Bok (Ecole Normale Superieure, Paris, France), who showed that many of the properties of the new high temperature superconductors can be understood just by the two-dimensional nature of their conduction bands. Other theoretical contributions stressed the importance of antiferromagnetic interactions in forming the superconducting state, or the possibility of a pairing of polarons. Several preliminary results of ongoing bandstructure calculations were presented. It was also argued that the highest $\mathrm{T}_{c}$ compound $\left(\mathrm{YBa}_{2} \mathrm{Cu}_{3} \mathrm{O}_{7}\right.$, $\mathrm{T}_{\mathrm{c}}=92 \mathrm{~K}$ ) could, in principle, still be a conventional $B C S$ superconductor. In that case, however, an extremely "strong coupling" would have implications on its specific heat and tunneling behavior. In the magnetism session, it was reported that undoped $\mathrm{La}_{2} \mathrm{CuO}_{4}$, which in its pure state is a semiconductor, can also show traces of superconductivity around $40 \mathrm{~K}$ after certain heat treatments.

Preliminary neutron scatting results from Brookhaven National Laboratory (USA) indicated antiferromagnetic order in semiconducting $\mathrm{La}_{2} \mathrm{CuO}_{4}$. Further evidence from susceptibility measurements was presented, which indicated antiferromagnetic order below $240 \mathrm{~K}$ in this compound. By an analysis of electron spin resonance spectra of powdered $\mathrm{YBa}_{2} \mathrm{Cu}_{3} \mathrm{O}_{7-\delta}$ at room temperature, the concentration of $\mathrm{Cu}^{3+}$ ions was deduced to be $20 \%$ of the total number of magnetic $\mathrm{Cu}$ ions. Muon spin rotation experiments were presented, and it was shown with Gd-substituted samples how the internal field distribution can be measured with this technique. The session ended with a description of the fabrication of a superconducting wire by powder metallurgy: a supercurrent density of $725 \mathrm{~A} / \mathrm{cm}^{2}$ was observed at $77 \mathrm{~K}$ in a $1-\mathrm{mm}$ diameter wire.

The discussion meeting ended with some short late-news contributions. In a brief summary the two chairs underlined the need to gather more experimental knowledge in order to prove or disprove the different theories for the new superconductors. Currently the biggest problems are the lack of single crystals and of good thin films.

\section{Photon, Beam and Plasma Enhanced Processing (Symposium A, Session 2)}

Symposium Organizers: V.T. Nguyen (CNET Grenoble, Meylan, France); A. Golanski (CNET Grenoble, Meylan, France); E.F. Krimmel (Siemens AG, Munich, West Germany).

Over 100 scientists from 13 countries attended Symposium A, which addressed the research and technology-based aspects of its scientific topic. Seventy-four papers were presented in two parallel sessions: Session A1 focused on photon-induced processing and rapid thermal annealing, while Session A2 focused on electron, ion and plasma processing, and processinduced defects. A joint session was held with Symposia B and C.

Before being split into parallel sessions, Symposium A started with a half-day joint session on the fundamentals of beam-solid interactions. The first of four invited papers was given by J.S. Foord (University of Oxford, UK), who presented an overview of recent results concerning the molecular mechanisms responsible for the photon-induced deposition of $W$ from $\mathrm{WF}_{6}$. An elegant paper, "Energy Exchange in Molecule-Surface Interaction and its Relation to Laser Chemical Processing," was then presented by K.L. Kompa (MaxPlanck-Institut für Quantenoptik, Munich, FRG). H. Kurz (Institut für Halbleitertechnik, Aachen, FRG) offered an overview of the current understanding of physical processes at the surface of laser-irradiated semiconductors and metals, focusing on recent results of time-resolved photoemission studies and time-of-flight measurements and their relevance to laser processing. Finally, R.M. Osgood (Columbia University, New York) presented a talk on physical phenomena in the laser-induced etching of semiconductors, with particular emphasis on complex and poorly understood photogenerated carrier effects.

Session A2 consisted of 9 invited papers and 39 contributions. Many of the contributions were based on the interdisciplinary approach required to connect technological applications to the basic interactions of energy beams with solids.

In Session A2 a new and promising approach to the investigation of dry etching/deposition reactions assisted by plasma, electron, ion or laser beams was presented by J. Dieleman (Philips Research Labs, Eindhoven, the Netherlands). Significant information on the composition of the reaction products leaving the surface, their kinetics, internal energy and angular distributions has been obtained using an angularly resolved time-of-flight technique.

Several lectures in this session were devoted to diagnostic techniques for in situ characterization of plasmas and surfaces. N. Sadeghi (University of Grenoble, France) presented an overview of the applications of optical spectroscopic diagnostic methods in monitoring plasma etching process parameters. A quasi-totality of these parameters has been made accessible using the spectroscopic approach. Interesting results obtained via in situ Auger analysis of silicon etched using halofluorocarbon plasmas were presented by E. Occhiello et al. (Instituto Guido Donegani, Novara, Italy). Experimental results showed the effect of ion energy on the surface composition and etch rates.

G. Wahl (Brown Boveri and Cie, Heidelberg, FRG) presented an overview of the state-of-the-art of plasma-enhanced CVD deposition. Deposition rates and deposition profiles were discussed in the light of simulation of processes and experimental results. The influence of the plasma conditions on the deposited structure was analyzed. Film growth mechanisms of hydrogenated amorphous silicon in plasma deposition were presented by J.C. Knights 
(Versatec, Xerox Company, Santa Clara, California) and J. Perrin (Ecole Polytechnique, Palaiseau, France). The conclusion of both presentations was to propose models for the film formation process that recognize both the importance of the precursor species and the surface reactions leading to film growth. An interesting lecture given by M.C. Habrard et al. (CNRS, Grenoble, France) proposed a novel PECVD process for amorphous hydrogenated silicon-nitride deposition. This technology appeared to be promising for the industrial development of insulating films.

Several informative papers focused on ion-beam-enhanced processing. E. Rimini (University of Catania, Italy) presented an overview of recent results concerning ionbeam-enhanced epitaxial regrowth of $S_{i}$ layers pre-amorphized by ion bombardment. Although the ion-beam-induced epitaxial regrowth rate depends on the impurity used to form the amorphous layer and on the substrate orientation, the corresponding activation energies do not change significantly for different impurities and orientations. The main changes are associated with the pre-exponential factors, which is consistent with earlier observations indicating that the mechanism involved is related to defect creation at the interface between crystalline and amorphous phases.

R.A. Zuhr et al. (Oak Ridge National Laboratory, Tennessee) presented a new approach to thin layer deposition - the ion beam deposition technique. The technique consists of accelerating and optically shaping the ion beam using a conventional ion implanter and subsequently electrostatically slowing down the ions before they reach the target. Some very promising results for low-temperature epitaxy for both semiconductors and metals were discussed.

Intriguing results on the conduction properties of ion-beam irradiated polymers were presented by J. Davenas et al (Universite Claude Bernard, Lyon, France). Ion bombardment converts the resists into new, carbon-enriched materials. Although, generally, the induced conductivity appears rather low and insufficient for the production of conducting patterns, very promising results were obtained using ion-beam-irradiated polyimide films.

C.W. White et al. (Oak Ridge National Laboratory, Tennessee) presented interesting results on the steam oxidation of silicon previously implanted with Ge ions. During the oxidation process $\mathrm{Ge}$ atoms are rejected from the oxide and trapped at the $\mathrm{Si} / \mathrm{SiO}_{2}$ interface. For thin oxides the presence of the Ge-rich layer leads to significantly higher oxidation rates compared with the standard steam-oxidation rates for $\mathrm{Si}$.

A complete and elegant review of recent investigations of electronic defects induced in silicon by the zone-melting recrystallization of SOI material, reactive ion etching and plasma-assisted nitridation of $\mathrm{SiO}_{2}$ and/or hydrogenation of thermal donors in Si was presented by A. Chantre (CNET Grenoble, France). G. Winterling (Energy and Process Technology, Munich, FRG) offered an extensive overview of both initial and light-induced defects in a-Si and a$\mathrm{Si}$ alloys (SiGex and $\mathrm{SiCx}$ ) in relation to device properties. These alloys appear viable for high efficiency solar cells if the gap state density can be reduced to values below $2 \times 10^{16} \mathrm{~cm}^{-3}$.

\section{Growth, Characterization, and Processing of III-V Materials with Correlations to Device Performances (Symposium B)}

Symposium Organizers: P.A. Glasow (Seimens AG Erlangen, West Germany); Y.I. Nissim (CNET Bagneux, France)

The emphasis of this three-day symposium was on material properties that are directly linked to device performance. Thirteen invited lectures and 40 contributions addressed the characterization of single-crystal substrates for large area monolithic integration as well as the characterization of heterostructures.

After the plenary lectures, the first session was devoted to bulk material growth. G. Muller (University of Erlangen) presented an overview of the state-of-the-art of InP bulk growth, underlining the problems of nonuniformity and the lack of reproducibility encountered in this material. GaAs bulk growth was reviewed by $L$. Zanotti (CMR, Maspec). The conclusion of both presentations was that the EPD of large diameter crystals ( 3 inches) can hardly be decreased in the LEC technique without lattice hardening.

The next session was devoted to thin film growth. An interesting lecture given by H.J. Scheel (Leybold-Heraeus) showed a sophisticated development of the LPE technique using rotating spirals to flatten out morphological surface steps.

Session 3 was a joint session with Symposia $A$ and C. J.F. Gibbons (Stanford University) presented the latest results obtained by the Limited Reaction Processing technique that was recently developed in his laboratory. In particular, formation of III-V heterostructures and $\mathrm{GaAs}$ on $\mathrm{Si}$ layer of excellent quality could be obtained.

Session 4 dealt with the identification of deep levels in III-V compounds. J.M. Spaeth (University of Paderborn) presented the use of spectroscopic methods like EPR, ODMR to elucidate the atomic structure of the defects. It was shown that, from the manufacturer's point of view, the material is still an unpredictable factor that can drastically affect fabrication yield.

Session 5 discussed the effects of processing technologies on large area IC fabrication. A. Cetronio (Selenia SpA) reviewed ion implantation processes. Rapid thermal annealing seems well controlled now, leading to uniformities comparable to state-ofthe-art furnace annealing. Photo etching in aqueous solutions was demonstrated to be a fast, reliable tool for investigating annealing technologies even with respect to point defects. S.K. Krawczyk (Ecole Centrale de Lyon) discussed photoluminescence imaging as a tool to assess the uniformity of electronical properties of semiconductor surfaces (InP, GaAs) during device processing. The same technique was utilized for the analysis of defect formation in annealed III-V layers.

L.F. Eastman (Cornell University) gave an invited presentation on device performances related to material parameters. $\mathrm{He}$ described the properties of heterojunctions for improved electron confinement in modulation-doped field-effect transistors. A switching time of 1 psec at all temperatures for the AlGaAs/InGaAs MODFET was predicted. The growth of strained layers of GaInAs on GaAs for MODFET fabrication was presented. Superior electron confinement was demonstrated through device performances $(20 \%$ increase in effective electron velocity as compared to a $\mathrm{GaAs}$ channel device). R. Germann reported a new fabrication process of beveled cross sections for high depth resolution of MQW structure.

The next session was devoted to the Growth of $\mathrm{GaAs}$ on $\mathrm{Si}$. The lectures were well attended and the discussions generated much interest. R. Fisher (AT\&T) reviewed the different devices fabricated on this material; K. Woodbride (Philips Research) lectured on the growth of GaAs and GaAs/AlGaAs multiple quantum well for a range of nucleation procedures and substrate orientations. Structural as well as optical qualities of these materials were discussed.

The following session focused on the problem of materials for lasers. The new DFB lasers emitting from the surface with GaAs-AlAs multilayers for mirrors were described by S. Wang (Berkeley). Lasers fabricated on GaAs-on-Si were also reported and the localized growth of $\mathrm{GaAs}$ was suggested to reduce the density of dislocations in the layers. The second invited talk of the session was presented by $B$. Sermage (CNET, Bagneux). The study of radiative and nonradiative recombination in III-V double heterostructures was reported. Auger recombination and interband absorption were shown to be respon- 
sible for the $\mathrm{T}_{\mathrm{o}}$ of InGaAsP lasers.

The final session was devoted to process related characterization. W. Jantz (Fraunhofer Institute, Freiburg) presented techniques such as Raman scattering, IR absorption, microwave absorption, luminescence to characterize impurities, and defects in processed layer.

\section{Amorphous Hydrogenated Carbon Films (Symposium C)}

Symposium Organizers: $P$. Oelhafen (Institut für Physik, Universität Basel, Switzerland); $P$. Koidl (Fraunhofer-Institut für, Angewandte Festkörperphysik, Freiburg, West Germany)

This symposium was devoted to the preparation, structure, properties, and applications of hard amorphous hydrogenated carbon films (a-C:H). This metastable carbonaceous material, sometimes called "diamondlike," is finding increasing application as an optical, dielectric, tribological, or corrosion resistant coating and as a material for wall conditioning in fusion devices. The meeting consisted of 11 invited and 45 contributed papers from Europe, the United Sates, Mexico, Israel, Japan, and Australia.

In the first session a categorization of dense hydrocarbon films based on different properties such as atom number density, mass density, and average coordination number was given by J.C. Angus (Cleveland, Ohio). The electronic structure of a-C:H was reviewed by J.L. Brédas (Namur, Belgium). Band structure calculations on chain-like compounds were used to model the various microscopic components present in hydrogenated amorphous carbon films. Full tight-binding calculations for various model structures and continuous random networks were performed by J. Robertson (Leatherhead, UK) and compared with experimental data like photoemission, optical, and $x$-ray near edge spectra.

In a joint session with Symposia $A$ and B, J.M.E. Harper (Yorktown Heights, New York) reviewed the importance of low energy ions in controlling thin film properties. Different ion beam techniques were described, including examples of depositing hard carbon films, reactive deposition of specific $\mathrm{Cu}$ oxide phases, and the synthesis of insulating $\mathrm{Zr}-\mathrm{N}$ and $\mathrm{Hf}-\mathrm{N}$ phases. The preparation of metastable films was reviewed by C. Weissmantel (Karl-MarxStadt, GDR). The emphasis was on hard carbon coatings, hard boron nitride films, and composites of the types $\mathrm{i}-\mathrm{C} / \mathrm{Me}$ and $\mathrm{i}$ $\mathrm{BN} / \mathrm{B}(\mathrm{Me}=\mathrm{Al}, \mathrm{Ti}, \mathrm{Cs}, \mathrm{W}$ or excess $\mathrm{B})$. The process for preparing diamond films by plasma-assisted CVD was discussed by R. Messier (University Park, Pennsylvania) in the same session. The history of diamond growth from the vapor phase, a review of the present state of the art of diamond film preparation, and future directions of research were also presented.

Process characterization was the subject of Session 3. The role of process gases, plasma chemistry and plasma surface interaction, and ion flux measurements in discharges during a-C: $\mathrm{H}$ deposition was discussed by several speakers ( $C$. Wild, Freiburg, FRG; Y. Cathérine, Nantes, France; N. Vedovotto, Villeurbanne, France). The growth of a-C:H on different metallic substrates was monitored by Auger electron spectroscopy (K.G. Tschersich, Jülich, FRG).

Session 4 covered film characterization. N. Savvides (Sydney, Australia) reviewed the optical properties in the $0.5-7.3 \mathrm{eV}$ energy range of a-C and a-C: $\mathrm{H}$ films prepared by magnetron sputtering in a pure argon and argon-hydrogen plasma. The discussion of optical measurements in this session was completed by B. Dischler and J. Wagner (Freiburg, FRG), who reviewed infrared spectroscopy, Raman, and luminescence spectroscopy on a-C:H films. A characterization of in situ prepared a-C:H films by photoelectron spectroscopy (UPS, $X P S)$ measurements and an investigation of the a-C:H/substrate interface was presented (P. Oelhafen, Basel, Switzerland). Auger electron and XPS depth profiling studies were discussed as well ( $P$. Sander, Münster, FRG). The emphasis of these measurements was on the formation of carbide-like phases in the interface region and its correlation with adhesion properties.

Many different applications of a-C:H were discussed in Session 5, with numerous examples given: durable antireflecting coatings for infrared optics, protection coatings for aluminized mirrors, photo thermal solar energy conversion, protection of optical fibers, medical uses in coating for orthopaedic pins, and mechanical applications in general (A.H. Lettington,
Malvern, UK). Further contributions spanned the application of a-C:H for surface modification of plastic insulators $(\mathrm{H}$. Kokai, Saitama, Japan), and in power electronics as insulated gates and corrosion resistant barriers (M.J. Mirtich, Cleveland, Ohio).

Session 6 was devoted to post deposition treatments such as transformations in a-C:H induced by ion and laser beams (R. Kalish, Haifa, Israel), hydrogen release by $\mathrm{MeV}$ ion irradiation $(\mathrm{H}$. Baumann, Frankfurt, FRG) and the modification of carbon layers on steel by ion bombardment. The reaction of atomic hydrogen with plasma-deposited a-C:H films was discussed by $E$. Vietzke (Jülich, FRG).

The poster session dealt with related materials. Different films presented here included hydrogen-free amorphous carbon, silicon-carbon alloys prepared from silane-propane mixtures, amorphous $\mathrm{Ge} / \mathrm{C}$ for infrared coating applications, plasma deposited a-C:H, F and a-Si/C:N:H films. Composites of metal containing hydrogenated carbon films were analyzed in several contributions. Other contributions dealt with subjects such as hydrogenimplanted graphite, thermal gas effusion from a-C:H films, adherence and stress in diamond-like carbon films, and electronbeam-induced conductivity changes in a$\mathrm{C}: \mathrm{H}$.

A special session was devoted to the application of a-C:H in fusion research. Wall conditioning by deposition of a-C:H films onto all plasma facing surfaces of fusion devices has led to significant improvements of the plasma performance (J. Winter, Jülich, FRG). The session concluded with contributions dealing with carbon coatings in the JET vessel, ion-beaminduced hydrogen release and isotopic exchange in carbonization layers, characterization of a-C:H coatings in the TEXTOR tokamak by optical interference colors and Rutherford backscattering.

\section{E-MRS}

For information on membership and activities of the European Materials Research Society, contact:

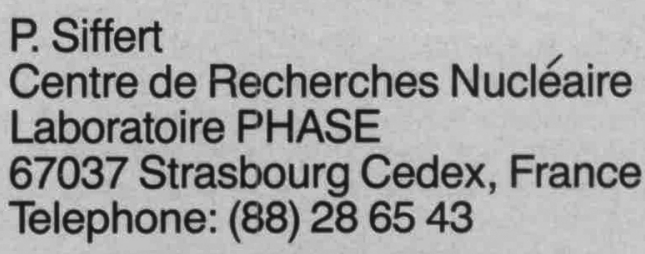




\section{S $N$ and Springer Series in Surface Science}

\section{Chemical Processing with Lasers \\ D. Baüerle}

Presents a view of the technique which permits maskless single-step patterning of materials within dimensions ranging from a few tenths of a micrometer up to several centimeters. Various possible processing applications include coating and etching of materials, surface modification and synthesis. This book gives the first comprehensive survey of the fundamental mechanisms and diverse applications of this new field of research and technology.

$1986 / 245 \mathrm{pp} . / 88$ illus./Hardcover $\$ 39.00$

ISBN 0-387-17147-9

Springer Series in Materials Science.

Vol. 1

\section{Laser-Beam Interactions with Materials}

Principles and Applications M. von Allmen

From a physicist's point of view, Laser-beam Interactions with Materials treats the wide variety of processes that lasers can induce in materials. Physical phenomena rang ing from optics to shock waves are discussed, as are applications in such diverse fields as semiconductor annealing, hole drilling, and fusion plasma production. The newcomer is given the necessary important background material, while the active research worker finds a critical and up-to-date review of the field.

1987/232 pp./71 illus./Hardcover

$\$ 52.00$

ISBN 0-387-17568-7

Springer Series in Materials Science,

Vol. 2

Laser Processing of Thin Films and Microstructures

Oxidation, Deposition and Etching of Insulators

I.W. Boyd

Contents: Introduction. Interaction and Kinetics. Experimental Considerations. Laser Assisted Thermal Oxidation and Nitridation. Passivation by Laser Annealing and Melting. Laser-Induced Deposition. Material Removal. Summary and Conclusions.

1987/approx. 280 pp./Hardcover

$\$ 60.50$ (tent.)

ISBN 0-387-17951-8

Springer Series in Materials Science.

Vol. 3

\section{Microclusters}

Proceedings of the First NEC

Symposium, Tokyo, Japan,

October 20-23, 1986

Edited by S. Sugano, Y. Nishina, and $\mathrm{S}$. Ohnishi

Microclusters presents recent advances in experimental and theoretical studies of clusters consisting of a few to a few hundred atoms of metallic or semiconducting elements. The topics covered iriclude both static and dynamic aspects of the atomic and electronic structure of these microclusters. $1987 / 289 \mathrm{pp} . / 187$ illus./Hardcover $\$ 56.00$

ISBN 0-387-17675-6

Springer Series in Materials Science. Vol. 4

\section{Low-Energy Electron Diffraction}

Experiment, Theory and Surface Structure Determination

M.A. Van Hove, W.H. Weinberg, and C.-M. Chan

Provides a comprehensive and detailed overview of the foundation, use, and application of LEED. The focus is placed on the structure determination of surfaces. Subjects include experimental and theoretical methods, surface crystallography and its results, and disordered surface structures and phase transitions. $1986 / 603$ pp./213 illus./Hardcover $\$ 69.00$

ISBN 0-387-16262-3

Springer Series in Surface Science, Vol. 6

\section{Electronic Phenomena in} Adsorption and Catalysis on Semiconductors and Dielectrics V.F. Kiselev and O.V. Krylov

Examines the close relationship between the electronic processes taking place on semiconductor-dielectric surfaces on the one hand and adsorptive and catalytic phenomena on the other. Prepared by a physicist-chemist team, the volume assembles and generalizes a great deal of surface and interface science. It also considers control methods for these processes and the mechanics for elementary acts of surface charging during adsorption and catalysis. $1987 / 279 \mathrm{pp} . / 76$ illus./Hardcover $\$ 100.70$

ISBN 0-387-17514-8

Springer Series in Surface Science, Vol. 7

\section{Kinetics of Interface Reactions}

Proceedings of a Workshop on Interface Phenomena, Campobello Island, Canada, September 25-27, 1986

Edited by M. Grunze and H.J. Kreuzer

In addition to the 6 invited papers, this volume contains chairmen summaries that include highlights of lively discussions of opposing views, as well as 12 contributed papers. Contents: Adsorption-Desorption Kinetics: Dynamics versus Thermodynamics. Precursors: Myth or Reality? Kinetics of Phase Transitions at Surfaces. 1987/299 pp./152 illus./Hardcover $\$ 55.00$

ISBN 0-387-17821-X

Springer Series in Surface Science, 10l. 8

also available . .

The Quantum Hall Effect

Edited by R.E. Prange and

S.M. Ginin

This is the first full-scale overview of the quantum hall effect. The contributors are leaders in the original research, and the book is organized and edited to provide a coherent introduction for the nonspecialist or graduate students.

"An interesting foreword has been written by Klaus von Klitzing on the discovery and some of the early experiments that he and his group made in the early 1980s."

Philosophical Magazine B

1986/419 pp./116 illus./4 tables/Hardcover $\$ 27.50$

ISBN 0-387-96286-7

Graduate Texts in Contemporary Phusics

To order by phone, please call 1-800-526-7254 (toll free), or in NJ, call 201. 348-4033. For mail orders, please be sure your payment includes $\$ 2.50$ for postage. $\mathrm{NY}$ $\mathrm{NJ}$ and $\mathrm{CA}$ residents please add sales tax. We accept Visa, MasterCard, and American

Express charges with expiration dates noted. as well as personal checks and money orders.

Springer-Verlag New York, Inc. Attn: Ken Quinn, Dept. S 739

175 Fifth Avenue New York, NY 10010

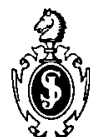

\section{Springer-Verlag}

New York Berlin Haidelbeng Vienne London Panis Tokyo 